\title{
Are the apple maggot, Rhagoletis pomonella, and blueberry maggot, $R$. mendax, distinct species? Implications for sympatric speciation
}

\author{
Jeffrey L. Feder, ${ }^{1}$ Charley A. Chilcote ${ }^{2}$ \& Guy L. Bush

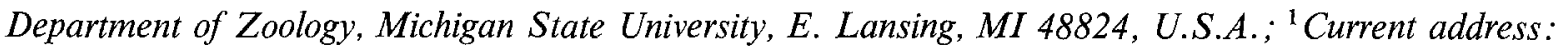 \\ Program in Ecology, Evolution and Behavior Department of Biology, Princeton University, Princeton, NJ \\ 08544; ${ }^{2}$ Current address: Department of Natural Resources, University of Michigan, Ann Arbor, MI \\ 48109, U.S.A.
}

Accepted: January 17, 1989

Key words: Rhagoletis pomonella, apple maggot fly, Rhagoletis mendax, blueberry maggot fly, sibling species, allozymes, sympatric speciation

\begin{abstract}
Rhagoletis pomonella (Walsh) and $R$. mendax (Curran) (Diptera: Tephritidae) are major economic pests of apple and blueberry fruits, respectively, in eastern North America. The taxonomic status of these flies as distinct species has been in dispute because of their close morphological similarity, broadly overlapping geographic distributions and inter-fertility in laboratory crosses. Starch gel electrophoresis of soluble proteins was performed to establish the extent of genetic differentiation and levels of gene flow between blueberry infesting populations of $R$. mendax and apple and hawthorn infesting populations of $R$. pomonella. $R$. mendax and $R$. pomonella were found to be genetically distinct sibling species as eleven out of total of twenty-nine allozymes surveyed possessed species specific alleles. Data from three sympatric apple and blueberry fly populations in Michigan indicated that these flies do not hybridize in nature and gave no evidence for nuclear gene introgression. Differences in host plant recognition were implicated as important pre-mating barriers to gene flow between $R$. pomonella and $R$. mendax; a result supporting a sympatric mode of divergence for these flies.
\end{abstract}

\section{Introduction}

The taxonomic distinction between the apple maggot fly, Rhagoletis pomonella (Walsh), and the blueberry maggot fly, $R$. mendax (Curran), has been argued throughout this century. Confusion stems from the fact that these flies are morphologically very similar, have broadly sympatric geographic distributions and produce viable and fertile progeny in laboratory crosses (Bush, 1966; J. Frey, pers. comm.). Morphological differences in ovipositor length, femur coloration and wing band ratios led Bush (1966) to conclude that $R$. pomonella and $R$. mendax were distinct species. However, others consider $R$. pomonella and $R$. mendax to be potentially interbreeding host races rather than species (Diehl \& Prokopy, 1986).

Determination of the level of gene flow and genetic divergence between apple and blueberry flies has important implications to models of sympatric speciation proposed for certain Rhagoletis species groups (Bush, 1969a, 1975). Because adult Rhagoletis flies mate almost exclu- 
sively on or near the fruits of their host plant (Bush, 1969b, Prokopy et al., 1971, 1972), mate choice is directly coupled to host selection. Variation for behaviors involved in host plant recognition may, therefore, produce pre-mating barriers to gene flow and result in the sympatric divergence of fly populations adapted to different hosts. Although host related phenotypic differences do not exist between $R$. pomonella and $R$. mendax, these flies still overlap in their host acceptance behaviors, host associated larval survivorship and adult emergence times (Diehl \& Prokopy, 1986; Bierbaum \& Bush, 1988 and submitted). Movement of R.pomonella and $R$. mendax between hosts with subsequent 'hybridization' is therefore possible under circumstances where blueberries (Vaccinium spp.) and huckleberries (Galyussacia spp.), the two primary Ericaceous hosts for $R$. mendax, are present in close proximity to domestic apples (Malus pumila) and hawthorns (Crataegus spp.), the primary Rosaceous hosts for $R$. pomonella. If substantial gene flow occurs between sympatric apple and blueberry maggot populations then $R$. pomonella and $R$. mendax should be recognized as 'host races' or 'biotypes' and some form of geographic isolation would probably be necessary for these flies to speciate.

Previous allozyme work revealed that although $R$. mendax and $R$. pomonella are very closely related, they do differ at the fumarase locus for which the common allele in $R$. mendax is absent from $R$. pomonella populations (Berlocher, 1980; Berlocher \& Bush, 1982). This result suggests that either (1) gene flow is restricted at least unidirectionally from $R$. mendax to $R$. pomonella or (2) selection against $R$. mendax larvae in apples is intense and correlated with the fumarase locus. Larval survivorship studies, however, have shown only moderate selective differences associated with the host fruit environment (Bierbaum \& Bush, submitted). Larval selection, therefore, cannot account for the absence of the $R$. mendax fumarase allele in $R$. pomonella populations. Nevertheless, concern was expressed that apple and blueberry flies used in the allozyme study originated from populations located hundreds of kilometers apart and that few populations and individual flies were analyzed (Diehl \& Prokopy, 1986).

The current electrophoretic study examines the extent of hybridization and genetic divergence between $R$. pomonella and $R$. mendax. The experiment addresses problems with the earlier work by genetically analyzing several sympatric fly populations in western Michigan, U.S.A., as well as geographically distant populations from Nova Scotia, Canada, and Door County, Wisconsin, U.S.A. The results indicate that $R$. pomonella and $R$. mendax are genetically distinct and give no evidence that nuclear gene flow is occurring between these two sibling species in nature.

\section{Materials and methods}

Geographic and host distributions of flies. The geographic distribution of $R$. mendax is entirely contained within that of the more widespread $R$. pomonella in eastern North America (Bush, 1966). The blueberry maggot can be found from Nova Scotia, Canada, to Florida, U.S.A., and as far west as Michigan, U.S.A. R. mendax prefers Ericaceous host plants in the genera Vaccinium (blueberries) and Gaylussacia (huckleberries) whose fruits are similar in many respects (Bush, 1966). $R$. mendax larvae have also been reported infesting wintergreen (Gaultheria procumbens) and cranberries (Vaccinium oxycoccoides) but these two plants do not seem to be suitable for supporting large populations of the fly (Bush, 1966). In the northeastern United States and eastern Canada, $R$. mendax primarily attacks native low bush blueberries and huckleberries. From Michigan and New Jersey south to Florida, the fly can also be reared from domesticated high bush blueberries. A suggestion has been made that the high and low bush infesting forms of the blueberry maggot represent partially reproductively isolated host races (Diehl \& Prokopy, 1986).

The distribution of the apple maggot differs from that of the blueberry maggot in that it occurs continuously as far west as Minnesota, U.S.A. 
and in an isolated population in the highlands of Mexico. The apple maggot has also recently been introduced into several western states in the U.S.A. $R$. pomonella parasitizes a wide variety of Rosaceous hosts including apples, cherries, hawthorns, and occasionally plums, pears and rose hips (Herrick, 1920; Bush, 1966; Shervis et al., 1970; Prokopy \& Bush, 1972; Prokopy \& Berlocher, 1980). However, apple and hawthorn infesting populations of $R$. pomonella predominate across the range of the fly.

Sampling scheme. Apple and blueberry infesting flies were collected from both western and northeastern regions of $R$. mendax's range in Michigan and Nova Scotia (Fig. 1). All flies analyzed in the study were collected as larvae from infested fruit and were reared to adulthood in the laboratory. The Michigan collection consisted of three pairs of sympatric apple and the high bush blueberry infesting populations (Fig. 1, Table 1). Site 3 (MacMartin house) represents a location in Chickaming, Michigan, where host plants were in physical contact. At the other two sympatric Michigan sites, apple orchards and blueberry patches were separated by a distance of $1 \mathrm{~km}$, which is still well within the cruising range of Rhagoletis adults (Phipps \& Dirks, 1933; Bourne et al., 1934; Maxwell, 1968; Neilson, 1971). Apple and blueberry flies were collected at the
Table 1. Collecting sites for $R$. pomonella and $R$. mendax. Numerical designations are given for sites along with the year and host fruit sampled. $A=$ domestic apple, $B(H)=$ high bush blueberry, $B(L)=$ low bush blueberry, $H=$ hawthorn

\begin{tabular}{|c|c|c|c|}
\hline Site \# & Location & $\begin{array}{l}\text { Fruit } \\
\text { collected }\end{array}$ & $\begin{array}{l}\text { Year(s) } \\
\text { collected }\end{array}$ \\
\hline 1. & $\begin{array}{l}\text { Maple Island Rd, near } \\
\text { Sullivan, Mich., U.S.A. }\end{array}$ & $\mathrm{A}, \mathrm{B}(\mathrm{H})$ & 84,85 \\
\hline 2. & $\begin{array}{l}\text { Highway } 46 \text {, near Moore- } \\
\text { land, Mich., U.S.A. }\end{array}$ & $\mathrm{A}, \mathrm{B}(\mathrm{H})$ & 84,85 \\
\hline 3. & $\begin{array}{l}\text { MacMartin home, Chick- } \\
\text { aming, Mich., U.S.A. }\end{array}$ & $\mathrm{A}, \mathrm{B}(\mathrm{H})$ & 84,85 \\
\hline 4. & $\begin{array}{l}\text { 112th Street, Grant, } \\
\text { Mich., U.S.A. }\end{array}$ & $\mathrm{H}$ & 85 \\
\hline 5. & $\begin{array}{l}\text { Ephraim, Door Co., Wisc., } \\
\text { U.S.A. }\end{array}$ & $\mathrm{H}, \mathrm{A}$ & 85 \\
\hline 6. & $\begin{array}{l}\text { Research Station, Kent- } \\
\text { ville, Nova Scotia, Can- } \\
\text { ada }\end{array}$ & A & 85 \\
\hline 7. & $\begin{array}{l}\text { Parrsboro, Nova Scotia, } \\
\text { Canada }\end{array}$ & $B(L)$ & 85 \\
\hline
\end{tabular}

Michigan sites in both 1984 and 1985, with the exception that a blueberry crop failure prevented collecting at site 1 in 1985 . $R$. pomonella flies were also sampled from hawthorns near Grant, Michigan (site 4) in 1985 and from hawthorns and apples outside of the range of $R$. mendax in Door Co., Wisconsin (site 5) in 1985.

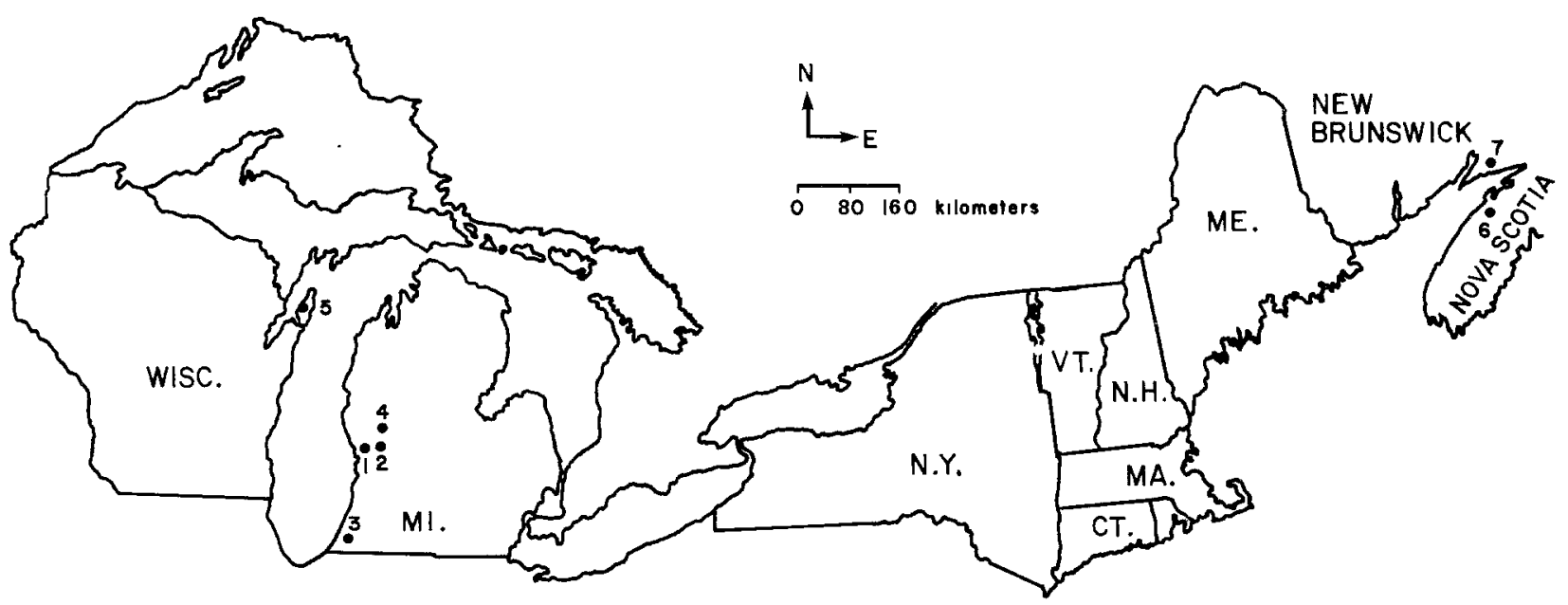

Fig. 1. Collecting sites for $R$. mendax and $R$. pomonella across the eastern United States and Canada. Site designations and descriptions are given in Table 1. 
Flies from Nova Scotia were kindly supplied by Dr. Willis Neilson. R. pomonella were collected from apples in 1985 on the grounds of the agricultural research station in Kentville, Nova Scotia (site 6). $R$. mendax were sampled from endemic low bush blueberries in 1985 near Parrsboro, Nova Scotia (site 7), which is located approximately $100 \mathrm{~km}$ northwest of Kentville.

Electrophoresis. Standard starch gel electrophoretic techniques were used and are described fully elsewhere (Berlocher \& Bush, 1982; Feder et al., in press). Only adult flies were analyzed electrophoretically. Electromorphs were numerically designated according to their relative anodal mobilities with the most common allele at a locus for $R$. pomonella assigned a mobility of 100 and used as a standard. Isozymes that migrated the nearest to the cathode were designated system 1 , the second nearest system 2, etc. A genetic basis has been established for all of the polymorphic loci scored in this study except for $N A D H$ diaphorase-3 (Berlocher \& Smith, 1983; Feder et al., in press; S. Berlocher, pers. comm.).

Data analysis. Significant deviations from Hardy-Weinberg genotypic expectations were determined by $G$-test. Alleles were pooled, as required, so that the genotype numbers of all classes were $\geq 1$. The Levene correction (Spiess, 1977) was applied for sample sizes of $<100$ or if genotypic classes had expected numbers $<1$. $G$-contingency statistics were used to test for allele frequency heterogeneity. $G$-tests were performed on allele numbers rather than on frequencies to give a weighted $G$ value for each test. Alleles for a locus were pooled, when necessary, to ensure that each cell in the $G$-test had an observed number $\geq 5$. F-statistics were calculated by the method of Weir and Cockerham (1984) with variances estimated by jackknifing over populations or loci. Linkage disequilibrium was determined between non-allelic genes using the method of Burrows (Cockerham \& Weir, 1977). Burrows disequilibrium values $(\Delta)$ were tested for significance by single degree of freedom Chi-square tests (Cockerham \& Weir, 1977). Genetic distance measures were derived by the formula of Nei (1972) with variances estimated by jackknifing over loci.

\section{Results}

Twenty-nine allozyme loci were resolved electrophoretically (see Table 2 for a list of these enzymes along with their abbreviations). Fourteen loci were either monomorphic or showed limited

Table 2. Allozymes resolved for $R$. pomonella and $R$. mendax. Enzyme abbreviations are given in parentheses

\begin{tabular}{|c|c|c|c|}
\hline \multicolumn{2}{|c|}{ Monomorphic or essentially fixed enzymes } & \multicolumn{2}{|l|}{ Polymorphic enzymes } \\
\hline Napthyl-acid phosphatase & $(A c p h)$ & Aminoacylase & $(A c y)$ \\
\hline Aconitase-1 & $($ Acon- 1$)$ & Aconitase-2 & $($ Acon-2) \\
\hline Alcohol Dehydrogenase-1 \& 2 & $(A d h-1 \& 2)^{*}$ & Adenylate kinase & $(A k)$ \\
\hline Aldolase & (Aldo) & Aspartate amino transferase $1 \& 2$ & $($ Aat-1 \& 2) \\
\hline NADH-diaphorase-1 & $($ Dia-1) & NADH-diaphorase-2 \& 3 & $($ Dia- $2 \& 3)$ \\
\hline Hexokinase & $(H k)$ & Fumarase & (Fum) \\
\hline Malate dehydrogenase- $1 \& 2$ & $(M d h-1 \& 2)^{*}$ & $\beta$-Hydroxyacid dehydrogenase & $(H a d)$ \\
\hline Peptidase-1 \& 3 & $($ Pep $1 \& 3)$ & Isocitrate dehydrogenase & $(I d h)$ \\
\hline Superoxide dismutase & (Sod) & Malic enzyme & $(M e)$ \\
\hline Trehalase & $($ Tre $)$ & Mannose phosphate isomerase & $(M p i)$ \\
\hline \multirow[t]{3}{*}{ Triose phosphate isomerase } & $(T p i)$ & Peptidase-2 & $($ Pep-2) \\
\hline & & Phosphoglucose isomerase & $(P g i)$ \\
\hline & & Phosphoglucomutase & $(P g m)$ \\
\hline
\end{tabular}

* Indicates an essentially fixed locus with the frequency of the common allele $>0.95$. 
variability (frequency of the common allele greater than $95 \%$ ) for the same allele in both blueberry and apple populations (Table 2). The remaining 15 loci were polymorphic in either $R$. mendax or $R$. pomonella (Table 2; Appendices 1 and 2). Most polymorphic loci, excluding Aat- 1 which is sex-linked (Feder etal., in press), were in Hardy-Weinberg equilibrium (data not shown). The 17 significant deviations observed in 298 tests did not differ appreciably from the number expected due to random type I error. The same was also true for the sex-linked allozyme Aat-1 for females in that no significant deviation from Hardy-Weinberg equilibrium was observed for the locus out of 13 tests (females are the homogametic sex in Diptera).

$R$. mendax and $R$. pomonella were found to be genetically distinct sibling species. Although none of the 15 polymorphic loci resolved in the study was diagnostically fixed for alternative alleles in $R$. mendax and $R$. pomonella populations, 'species-specific' alleles were found for 11 different allozymes (Aat-1 \& 2, Dia-2 \& 3, Acon-2, Acy, Pep-2, Fum, Pgi, $A$ k and $\mathrm{Had}$; see Appendices 1 and 2). In addition, $M e$ showed highly significant gene frequency differences ( 0.40 or more) between sympatric apple and blueberry populations in Michigan (Appendix 1).

Species-specific alleles were not always present in high frequencies in $R$. pomonella or $R$. mendax populations. For instance, $A k^{111}$ and $\mathrm{Had}^{97}$ generally had frequencies of $5 \%$ or less for $R$. pomonella and $R$. mendax, respectively (Appendix 2). However, the common alleles for the allozymes Aat-1 and Dia-2 in R. pomonella were not present in any of the Michigan or Nova Scotia populations of $R$. mendax (Appendices 1 and 2). Conversely, Fum ${ }^{158}$ and Dia-3 ${ }^{91}$, the common alleles in $R$. mendax populations, were virtually absent from $R$. pomonella populations. One Fum $^{158}$ and two Dia- $3^{91}$ alleles were scored for one apple infesting fly at site 3 (Chickaming, Michigan) in 1985 (Appendix 2). However, no other fly reared from apples possessed either of these two alleles.

The genotype of the aberrant apple infesting fly from Chickaming, Michigan, implies that it is
$R$. mendax and not either $R$. pomonella or a F1 hybrid. Dia-3 gene frequencies for $R$. mendax and $R$. pomonella at site 3 (Appendix 2) indicate that a F1 hybrid could be either heterozygous for Dia- $3^{91} / D i a-3^{100}$ or homozygous for Dia- $3^{100}$ but not homozygous for Dia- $3^{91}$ as the aberrant fly is. Also, $18 \%$ of the blueberry flies analyzed at site 3 have the same two locus genotype for Fum and Dia-3 as the fly in question while no other apple fly does. Furthermore, if Dia-3 and Fum are excluded from consideration, the probability of possessing the same genotype as the aberrant fly for the remaining 13 polymorphic loci is approximately $1 \times 10^{-12}$ for an apple fly. In comparison, a blueberry fly has a more reasonable probability of $2 \times 10^{-4}$ of being genetically identical.

F-statistics and genetic distance measures were calculated to quantify the amount of genetic divergence between $R$. mendax and R.pomonella. F-statistics derived by the method of Weir and Cockerham (1984) based on all 15 polymorphic loci revealed an overall $\mathrm{F}_{\mathrm{ST}}$ value of $0.3106 \pm 0.0600$ (jackknife estimate of standard deviation calculated over loci) among apple and blueberry fly populations in 1985. This level of genetic differentiation is not atypical of values for other insect species and is at least an order of magnitude greater than reported intraspecific $\mathrm{F}_{\mathrm{ST}}$ values (McCauley, 1987). Apple and blueberry flies were separated by an overall Nei genetic distance of $0.230 \pm 0.078$ (jackknife estimate of standard deviation calculated over loci) based on all 29 loci resolved in the study. The amount of genetic differentiation between $R$. mendax and $R$. pomonella was suprising because previous work (Berlocher \& Bush, 1982) suggested that the sibling species were much more closely related being separated by a Nei distance of only 0.0750 . It should be noted, however, that the Nei distance derived in the earlier work was based on a set of allozyme loci that only partially overlapped with that of the current study. For example, staining methods for Aat-1, Dia-2 and Dia-3 (three loci which have species specific alleles in high frequencies) were not perfected in Rhagoletis at the time of Berlocher and Bush's (1982) original survey of the genus. 
Genetic analysis of hawthorn flies from Michigan and Wisconsin showed that they are very closely related to apple flies sharing all electromorphs in common (Appendices 1 and 2). Nei distances of only $0.0080 \pm 0.0039$ and $0.0112 \pm 0.0062$ were calculated between hawthorn and apple flies from Michigan and Wisconsin, respectively. These Nei distances fall within the range of values normally found for intra-specific comparisons between insect populations (see Figure 2 of Menken \& Ulenberg, 1987). In addition, none of the unique $R$. mendax alleles was observed in any other hawthorn population of $R$. pomonella. This result suggests that reproductive isolation between hawthorn and blueberry flies is as complete as that between apple and blueberry flies. Sympatric hawthorn and blueberry sites are needed, however, to entirely rule out the possibility of introgression between these flies.

The electrophoretic data also lend little support for the suggestion of Diehl and Prokopy (1986) that low and high bush blueberry maggot populations represent partially reproductively isolated host races, as the overall Nei genetic distance between low and high bush forms of $R$. mendax $(0.0111 \pm 0.0047)$ was not significantly different from the value between apple populations of $R$. pomonella from Michigan and Nova Scotia $(0.0073 \pm 0.0031)$. Observed frequency differences between blueberry fly populations are therefore most likely due to geographic differentiation. Verification of this point, however, requires analysis of sympatric high and low bush blueberry populations.

Hybridization is rare, if it occurs at all, between sympatric blueberry populations of $R$. mendax and apple infesting $R$. pomonella. The diagnostic alleles for Fum, Dia-2, and Dia-3 can be used to calculate a statistical confidence level for hybridization between blueberry and apple flies. Based on genotypic frequencies at the three sympatric Michigan sites, whenever $R$. pomonella and $R$. mendax mate approximately $43 \%$ of the resulting F1 hybrid offspring should be triple locus heterozygotes for Fum, Dia-2, and Dia-3. No fly was heterozygous for all three loci, however, out of a total of 654 flies analyzed; a result significant at the $P \leq 0.05$ level assuming a Poisson distribution with hybridization occurring at a frequency of $1.06 \%$ or greater.

The preceeding analysis assumes that Fum, Dia-2, and Dia-3 are in linkage equilibrium and that viabilities are the same for hybrid larvae as they are for conspecific crosses. To determine the extent of genetic co-variation among Fum, Dia-2, and Dia-3, correlation coefficients based on Burrows disequilibrium values (Cockerham \& Weir, 1977) were calculated between pairs of nonallelic genes. Significant disequilibrium was not observed for any test involving Fum, Dia-2, and Dia-3 (data not shown) and, therefore, gene frequencies at these three loci appear to be evolving independently. The assumption of normal survivorship for F1 hybrid progeny may not be completely valid, however. Fecundities for interspecific matings, as measured by survivorship of F1 progeny to adulthood, can vary widely from cross to cross and may be reduced by as much as $50 \%$ compared with conspecific matings (W. Neilson, pers. comm.). However, unless tri-locus heterozygotes for Fum, Dia-2, and Dia-3 have disproportionately lower viabilities (which is doubtful), R. mendax $\times R$. pomonella crosses would still produce genotypically distinguishable hybrids. The frequency of detecting F1 hybrids, should, therefore, be reduced only in relation to the general decrease in hybrid survivorship.

Intraspecific allele frequencies were reasonably consistent across years at the Michigan sites. Six out of a total of $75 \mathrm{G}$-contingency tests indicated significant gene frequency differences across years at a given location (Table 3 ). Although the number of significant tests is higher than that expected by random type I error, the most pronounced frequency difference observed between 1984 and 1985 was 0.170 for $P e p-2^{110}$ for apple flies at site 1 (Appendix 1). Nei genetic distances based on only the 15 polymorphic loci were just 0.0030 in comparisons of pooled $R$. mendax populations between 1984 and 1985 and 0.0047 for $R$. pomonella populations.

Geographic variation was apparent across both $R$. mendax and $R$. pomonella populations. 
Table 3. G-contingency tests for allele frequency heterogeneity across years and sites for $R$. mendax and $R$. pomonella populations (degrees of freedom for tests are given in parentheses). Allele frequencies for loci not showing significant variation within Michigan were pooled across populations and tested against the corresponding host population in Nova Scotia (N.S.) or Wisconsin. Acon-2, Fum and Pgm for R. mendax were tested on a site by site basis between Michigan and N.S.

\begin{tabular}{|c|c|c|}
\hline Test & R. mendax & R. pomonella \\
\hline $\begin{array}{l}\text { Between years ('84-'85) at a } \\
\text { given site }\end{array}$ & Acon-2/Site $3(3)^{*}$ & $\begin{array}{l}\text { Aat }-2 /\left[\text { Site } 1(3)^{*}, \text { Site } 2(3)^{*}\right] \\
\text { Acon }-2 /\left[\text { Site } 1(4)^{*}, \text { Site } 2(4)^{*}\right] \\
\text { Pep }-2 /\left[\text { Site } 1(2)^{*}\right]\end{array}$ \\
\hline Among Michigan sites ('84) & $\operatorname{Pgm}(2)^{* * *}$ & $\begin{array}{l}\text { Acon-2 }(8)^{* * * *}, \text { Aat }-2(6)^{*} \\
\operatorname{Me}(2)^{*}, \operatorname{Mpi}(2)^{*}, \operatorname{Pgm}(2)^{* *}\end{array}$ \\
\hline Among Michıgan sites ('85) & $\begin{array}{l}\text { Acon-2 }(3)^{* *}, \operatorname{Pgm}(1)^{* * * *} \\
\text { Fum }(1)^{* *}\end{array}$ & \\
\hline $\begin{array}{l}\text { Between pooled Michigan sites } \\
\text { and Nova Scotia (N.S.) ('85) }\end{array}$ & $\begin{array}{l}\operatorname{Had}(1)^{*}, \operatorname{Me}(1)^{* *} \\
\operatorname{Pgi}(1)^{* *}\end{array}$ & $\begin{array}{l}\text { Acon-2 }(4)^{* * *}, \text { Aat }-2(3)^{* *} \\
\text { Aat-1 }(1)^{*}, \text { Me }(1)^{* *} \\
\text { Pep-2 }(2)^{*}, \text { Pgi }(1)^{* *}\end{array}$ \\
\hline $\begin{array}{l}\text { Between site 2/N.S. ('85) } \\
\text { (Tests for Acon-2, Fum, Pgm) }\end{array}$ & $\begin{array}{l}\operatorname{Acon}-2(3)^{* * * *}, \text { Fum }(1)^{* * * *} \\
\operatorname{Pgm}(1)^{* *}\end{array}$ & - \\
\hline $\begin{array}{l}\text { Between site 3/N.S. ('85) } \\
\text { (Tests for Acon-2, Fum, Pgm) }\end{array}$ & $\begin{array}{l}\operatorname{Acon}-2(3)^{* * *} \\
\operatorname{Pgm}(1)^{*}\end{array}$ & - \\
\hline $\begin{array}{l}\text { Between pooled Michigan apple sites } \\
\text { and Wisconsin apple sites ('85) }\end{array}$ & - & $\operatorname{Had}(1)^{* *}$, Acon- $2(2)^{* * *}$ \\
\hline
\end{tabular}

*P $P 0.05, * * P \leq 0.01, * * * P \leq 0.001$.

Overall $\mathrm{F}_{\mathrm{ST}}$ values were significantly greater than zero in 1985 across both $R$. mendax and $R$. pomonella populations $(0.0399 \pm 0.0126$ and $0.0157 \pm 0.0070$, respectively). Nine out of a total of $60 \mathrm{G}$-contingency tests indicated significant intraspecific allele frequency differences among Michigan populations in 1984 and 1985 (Table 3). Allele frequencies for loci not showing significant variation among Michigan populations in 1985 were pooled and tested for heterogeneity against populations from the same host in Nova Scotia and Wisconsin. Six out of a total of 15 loci tested showed significant allele frequency differences between apple maggot flies from Michigan and Nova Scotia while 2 of 15 tests were significant between Michigan and Wisconsin (Table 3). Acon $^{75}$ and $\mathrm{Pgm}^{111}$, found in Michigan $R$. pomonella populations at average frequencies of 0.193 and 0.055 , respectively, were not observed at the Kentville, Nova Scotia site (Appendix 1). All but the rarest alleles were shared in common, however, between Wisconsin and
Michigan populations of $R$. pomonella. Six loci also displayed significant frequency differences between blueberry flies from Nova Scotia and at least one of the Michigan sites (Table 3). Acon ${ }^{95}$, present in Michigan $R$. mendax populations at an average frequency of 0.196, was absent from the Parrsborro, Nova Scotia population (Appendix $1)$.

\section{Discussion}

The allozyme results verify that $R$. pomonella and $R$. mendax are genetically distinct species that hybridize rarely, if at all, in nature. Laboratory and field experiments indicate, however, that $R$. mendax and $R$. pomonella have the potential to hybridize whenever they come in contact. Furthermore, hybrid F1, F2 and backcross larvae produced from laboratory matings are viable and fertile and can be reared to adulthood in either apple or blueberry fruits (J. Frey, pers. comm.). 
Premating isolating barriers must, therefore, restrict hybridization between blueberry and apple flies.

What premating barrier(s) restricts hybridization between $R$. mendax and $R$. pomonella? Evidence exists to rule out a number of possibilities. For instance, long range pheromones are not important sexual attractants in the $R$. pomonella group (Boller \& Prokopy, 1976). Body coloration and wing pattern are believed to be species recognition cues during courtship within certain Rhagoletis species groups (Bush, 1966). However, the morphological similarity of $R$. mendax and $R$. pomonella and the ease with which these flies mate in the laboratory argue against strong ethological isolation. Blueberry flies eclose as adults approximately one week earlier than apple flies. However, sexually mature $R$. mendax and $R$. pomonella adults co-occur for over a month at all three sympatric sites in Michigan (J. Feder, pers. obs.). Allochronic isolation, therefore, does not appear to play a major role in maintaining species differences between blueberry and apple flies.

Differential host recognition is the most likely factor limiting contact between apple and blueberry flies. Significant differences have been found in the behavioral and chemosensory responses of $R$. mendax and $R$. pomonella to apples, hawthorns and blueberries (Diehl \& Prokopy, 1986: Bierbaum \& Bush, 1988; J. Frey, pers. comm.). Because $R$. mendax and $R$. pomonella mate almost exclusively on or near the fruits of their respective host plants (Prokopy et al., 1971, 1972), species specific differences in host identification could produce strong premating barriers to gene flow. The unique alleles possessed by $R$. mendax and $R$. pomonella make it possible to test host plant fidelity through a genetic analysis of adults captured directly from interdigitated blueberry and apple plants. Until this test is completed, indirect evidence related to the blueberry crop failure at site 1 (Sullivan, Michigan) in 1985 suggests that host recognition is accurate and species specific. $R$. mendax did not attack apples or show any sign of introgression with $R$. pomonella at Sullivan despite the fact that blueberries were absent from the site in 1985 and apples were the only readily available host fruit.

Host plant recognition, although accurate, may not be absolutely perfect for Rhagoletis flies. One fly reared from apples in this study did possess a genotype characteristic of $R$. mendax. One possible explanation is that $R$. mendax females occasionally lay their eggs into apples. If true, the results of this study suggest that such host identification mistakes are rare and have little effect on promoting nuclear gene flow between the two species. Plasticity in host recognition may, however, be important in an evolutionary sense in allowing $R$. pomonella group flies to colonize and establish permanent populations on new host plants. A second explanation is that the $R$. mendax fly in question became accidently mixed with $R$. pomonella flies during rearing. Indirect support for the second possibility comes from the fact that $R$. mendax females have difficulty puncturing the skin of certain domestic apple varieties with their ovipositors (Diehl \& Prokopy, 1986; Bierbaum \& Bush, 1988). These mechanical difficulties reduce the likelihood that a $R$. mendax female laid her eggs into apples at the MacMartin site.

The inability of $R$. mendax females to lay their eggs into several apple varieties normally infested by $R$. pomonella could be an important element isolating the two species. However, the difficulties $R$. mendax has ovipositing into apples do not prevent $R$. mendax females from mating with $R$. pomonella males if blueberry fly females alighted on apples or apple fly males landed on blueberries. Mated $R$. mendax females could subsequently deposit their eggs into blueberries thereby promoting gene flow between $R$. pomonella and $R$. mendax. Thus, contact between $R$. mendax and $R$. pomonella can result in hybridization and potential introgression in spite of differences in ovipositional preference. Furthermore, although $R$. mendax females have difficulty ovipositing into certain apple varieties, they have little trouble penetrating hawthorns (Diehl \& Prokopy, 1986), which are the native host of R. pomonella (Bush, 1966). However, genetic analysis of hawthorn flies suggests that they are as 
genetically distinct from $R$. mendax as apple flies are.

Post mating reproductive isolation may also limit introgression between $R$. pomonella and $R$. mendax. Although apple and blueberry flies can be easily crossed, viability to adulthood may be reduced by as much as $50 \%$ for hybrid progeny (W. Neilson, pers. comm.). Although F1 hybrids are fertile (J. Frey, pers. comm.), adequate studies have not been done to determine the extent to which hybrid breakdown occurs in F2 and backcross progeny. However, even if postmating isolation exists between $R$. pomonella and $R$. mendax as a result of hybrid breakdown, it would not stop the formation of F1 progeny. Because F1 hybrids were not observed in the field, differences in host recognition must limit hybridization between $R$. mendax and $R$. pomonella.

Assortative mating due to differences in host recognition behaviors is an important component of sympatric speciation models. The direct connection in Rhagoletis between host recognition and mate selection could result in the sympatric divergence of host associated populations in the absence of geographic barriers to gene flow. Unfortunately, we may never know the exact chronological order or geographic context of hosts shifts which occurred during the evolution of the $R$. pomonella group. Therefore, it is difficult to directly assess the involvement of host plant fidelity in the speciation process. Nevertheless, host preference differences certainly help maintain divergence between $R$. mendax and $R$. pomonella. In the absence of these differences it is conceivable that populations of blueberry and apple flies would fuse. More will be known about this possibility after studies on hybrid sterility and breakdown are completed. Such studies will also be useful in allowing us to fine tune our estimated confidence level of hybridization between $R$. mendax and $R$. pomonella. If, however, $\mathrm{F} 2$ and backcross progeny prove to be reasonably viable and fertile then it is difficult to see how host specificity could not have played an important role in speciation. Of course, whether host recognition differences arose in sympatry or allopatry

Appendix 1. Allele frequencies for Acon-2, Acy, Pep-2, Pgi, Me, Dia-2 and Pgm for R. mendax and R. pomonella populations across the eastern United States and Canada. Site designations are given in Table 1. Allele frequencies are only given for those electromorphs displaying the greatest amount of interspecific differentiation. A complete list of allele frequencies is available from the first author on request

\begin{tabular}{|c|c|c|c|c|c|c|c|c|c|c|c|c|c|c|c|c|c|}
\hline \multirow[t]{2}{*}{ Species } & \multirow[t]{2}{*}{ Site } & \multirow[t]{2}{*}{ Year } & \multirow[t]{2}{*}{ Host } & \multicolumn{2}{|c|}{ Acon-2 } & \multicolumn{2}{|l|}{ Acy } & \multicolumn{2}{|c|}{ Pep-2 } & \multicolumn{2}{|l|}{ Pgi } & \multicolumn{2}{|l|}{$\mathrm{Me}$} & \multicolumn{2}{|c|}{ Dia-2 } & \multicolumn{2}{|l|}{ Pgm } \\
\hline & & & & $\mathbf{N}$ & 75 & $\mathrm{~N}$ & 89 & $\mathrm{~N}$ & 110 & $\mathbf{N}$ & 145 & $\mathbf{N}$ & 80 & $\mathbf{N}$ & 100 & $\mathrm{~N}$ & 111 \\
\hline \multirow[t]{6}{*}{ R. mendax } & 1 & 84 & B & 87 & 0.000 & - & - & 13 & 0.000 & 79 & 0.000 & 39 & 0.051 & 62 & 0.000 & 78 & 0.051 \\
\hline & 2 & 84 & $\mathrm{~B}$ & 79 & 0.000 & - & - & 52 & 0.000 & 79 & 0.000 & 66 & 0.015 & 52 & 0.000 & 79 & 0.019 \\
\hline & 2 & 85 & B & 41 & 0.000 & 40 & 0.000 & 41 & 0.000 & 41 & 0.000 & 40 & 0.088 & 41 & 0.000 & 41 & 0.000 \\
\hline & 3 & 84 & B & 72 & 0.000 & - & - & 29 & 0.000 & 72 & 0.000 & 72 & 0.076 & 72 & 0.000 & 72 & 0.028 \\
\hline & 3 & 85 & B & 55 & 0.000 & 14 & 0.000 & 55 & 0.000 & 55 & 0.000 & 53 & 0.066 & 55 & 0.000 & 55 & 0.027 \\
\hline & 7 & 85 & B & 39 & 0.000 & - & - & 13 & 0.000 & 39 & 0.000 & 39 & 0.000 & 39 & 0.000 & 39 & 0.000 \\
\hline \multirow[t]{10}{*}{ R. pomonella } & 1 & 84 & A & 88 & 0.091 & - & - & 24 & 0.062 & 79 & 0.126 & 39 & 0.451 & 54 & 0.657 & 79 & 0.038 \\
\hline & 1 & 85 & A & 41 & 0.171 & 41 & 0.158 & 41 & 0.232 & 43 & 0.139 & 42 & 0.512 & 42 & 0.560 & 43 & 0.047 \\
\hline & 2 & 84 & A & 79 & 0.101 & - & - & 13 & 0.118 & 79 & 0.063 & 64 & 0.508 & 52 & 0.557 & 79 & 0.032 \\
\hline & 2 & 85 & A & 38 & 0.263 & 39 & 0.154 & 40 & 0.175 & 38 & 0.079 & 39 & 0.615 & 38 & 0.632 & 39 & 0.026 \\
\hline & 3 & 84 & A & 71 & 0.303 & - & - & - & - & 72 & 0.049 & 45 & 0.644 & 46 & 0.717 & 70 & 0.093 \\
\hline & 3 & 85 & $\mathrm{~A}$ & 44 & 0.227 & 44 & 0.125 & 44 & 0.239 & 45 & 0.100 & 45 & 0.622 & 45 & 0.656 & 45 & 0.089 \\
\hline & 4 & 85 & $\mathrm{H}$ & 169 & 0.068 & 166 & 0.208 & 169 & 0.172 & 157 & 0.080 & 156 & 0.256 & 169 & 0.843 & 156 & 0.010 \\
\hline & 5 & 85 & $\mathrm{H}$ & 51 & 0.000 & 51 & 0.167 & 51 & 0.216 & 51 & 0.079 & 51 & 0.196 & 51 & 0.765 & 51 & 0.039 \\
\hline & 5 & 85 & A & 49 & 0.010 & 50 & 0.130 & 50 & 0.150 & 51 & 0.069 & 52 & 0.539 & 50 & 0.700 & 51 & 0.030 \\
\hline & 6 & 85 & A & 39 & 0.000 & - & - & 13 & 0.077 & 39 & 0.025 & 39 & 0.398 & 39 & 0.731 & 39 & 0.000 \\
\hline
\end{tabular}


Appendix 2. Allele frequencies for Fum, Dia-3, Aat-1, Aat-2, Ak, and $H a d$ for $R$. mendax and $R$. pomonella populations across the eastern United States and Canada. Site designations are given in Table 1. Allele frequencies are only given for those electromorphs displaying the greatest amount of interspecific differentiation

\begin{tabular}{|c|c|c|c|c|c|c|c|c|c|c|c|c|c|c|c|c|}
\hline \multirow[t]{2}{*}{ Species } & \multirow[t]{2}{*}{ Site } & \multirow[t]{2}{*}{ Year } & \multirow[t]{2}{*}{ Host } & \multicolumn{2}{|c|}{ Fum } & \multicolumn{2}{|c|}{ Dia-3 } & \multicolumn{2}{|c|}{ Aat-1 } & \multicolumn{2}{|c|}{ Aat-2 } & \multicolumn{2}{|l|}{$\mathrm{Ak}$} & \multicolumn{3}{|l|}{ Had } \\
\hline & & & & $\mathrm{N}$ & 158 & $\mathbf{N}$ & 89 & $\mathrm{~N}$ & -100 & $\mathrm{~N}$ & 100 & $\mathrm{~N}$ & 111 & $\mathrm{~N}$ & 97 & 122 \\
\hline \multirow[t]{6}{*}{ R. mendax } & 1 & 84 & B & 89 & 0.775 & 89 & 0.848 & 44 & 0.000 & 86 & 0.000 & 59 & 0.000 & 89 & 0.011 & 0.888 \\
\hline & 2 & 84 & B & 79 & 0.798 & 79 & 0.892 & 66 & 0.000 & 79 & 0.000 & 75 & 0.000 & 79 & 0.000 & 0.785 \\
\hline & 2 & 85 & B & 41 & 0.829 & 41 & 0.927 & 41 & 0.000 & 41 & 0.000 & 41 & 0.000 & 41 & 0.000 & 0.793 \\
\hline & 3 & 84 & B & 72 & 0.701 & 72 & 0.917 & 72 & 0.000 & 72 & 0.000 & 72 & 0.000 & 72 & 0.014 & 0.771 \\
\hline & 3 & 85 & B & 54 & 0.630 & 55 & 0.936 & 55 & 0.000 & 54 & 0.000 & 55 & 0.000 & 55 & 0.054 & 0.736 \\
\hline & 7 & 85 & B & 39 & 0.910 & 39 & 0.744 & 39 & 0.000 & 39 & 0.000 & 39 & 0.000 & 39 & 0.000 & 0.885 \\
\hline \multirow[t]{10}{*}{ R. pomonella } & 1 & 84 & A & 89 & 0.000 & 89 & 0.000 & 48 & 0.844 & 85 & 0.247 & 58 & 0.000 & 89 & 0.000 & 0.258 \\
\hline & 1 & 85 & A & 42 & 0.000 & 31 & 0.000 & 42 & 0.809 & 42 & 0.214 & 42 & 0.000 & 48 & 0.000 & 0.274 \\
\hline & 2 & 84 & A & 79 & 0.000 & 79 & 0.000 & 66 & 0.803 & 78 & 0.263 & 78 & 0.000 & 79 & 0.000 & 0.278 \\
\hline & 2 & 85 & A & 39 & 0.000 & 39 & 0.000 & 39 & 0.769 & 39 & 0.295 & 39 & 0.013 & 40 & 0.000 & 0.263 \\
\hline & 3 & 84 & A & 72 & 0.000 & 72 & 0.000 & 50 & 0.880 & 72 & 0.208 & 71 & 0.007 & 71 & 0.000 & 0.232 \\
\hline & 3 & 85 & A & 45 & 0.022 & 42 & 0.024 & 44 & 0.784 & 45 & 0.233 & 44 & 0.046 & 45 & 0.000 & 0.311 \\
\hline & 4 & 85 & $\mathbf{H}$ & 169 & 0.000 & 169 & 0.000 & 155 & 0.774 & 154 & 0.399 & 157 & 0.003 & 170 & 0.000 & 0.121 \\
\hline & 5 & 85 & $\mathbf{H}$ & 51 & 0.000 & 51 & 0.000 & 50 & 0.900 & 51 & 0.441 & 50 & 0.000 & 51 & 0.000 & 0.176 \\
\hline & 5 & 85 & A & 50 & 0.000 & 50 & 0.000 & 50 & 0.700 & 50 & 0.300 & 50 & 0.020 & 50 & 0.000 & 0.150 \\
\hline & 6 & 85 & $\mathrm{~A}$ & 39 & 0.000 & 39 & 0.000 & 39 & 0.885 & 39 & 0.244 & 39 & 0.000 & 39 & 0.000 & 0.205 \\
\hline
\end{tabular}

would still be a matter of conjecture. However, genetic differences have been found between sympatric hawthorn and apple populations of R. pomonella (Feder et al., 1988; McPheron et al., 1988 ). The sympatric shift of $R$. pomonella from hawthorns to domesticated apples, which occurred within the last 150 years (Walsh, 1867), excludes the possibility of prior periods of geographic isolation. If differences in host recognition or some other inherent biological characteristics of apple and hawthorn flies can be related to the observed genetic differentiation, then taxa in the $R$. pomonella group are likely to diverge sympatrically by shifting and adapting to new host plants.

\section{Acknowledgements}

We thank S.M. Williams, B.A. McPheron and S.H. Berlocher for reading and providing useful comments on an earlier draft of this manuscript. We also appreciate the cooperation and friendship of Bill and Jody MacMartin in easing the drudgery of fly collecting. Sue Jamrog assisted in all aspects of fly rearing and Suzanne Tolin and Angela Sorrells provided much needed secretarial support.

\section{Résumé}

Est-ce que Rhagoletis pomonella et R. mendax constituent des espèces distinctes? Implications pour la spéciation sympatrique

$R$. pomonella Walsh and $R$. mendax Curran sont respectivement deux mouches très nuisibles aux pommes et aux myrtilles du N E des USA. La position taxonomique de ces mouches comme espèces distinctes a été longtemps mise en doute par suite de leur grande ressemblance morphologique, de l'important chevauchement de leurs répartitions et de leur interfécondité au laboratoire. L'électophorèse sur gel d'amidon de protéines solubles a été utilisé pour établir l'importance de la différenciation génétique et du flux génique entre $R$. mendax contaminant des myrtilles et $R$. pomonella contaminant des pommiers et des 
aubépines. $R$. mendax et $R$. pomonella se sont révélées des espèces jumelles car, à l'exception de 11 alolozymes sur 29 , chaque espèce possédait des allèles spécifiques. Les données concernant 3 populations sympatriques de mouches des myrtilles et des pommes du Michigan ont montré que des mouches ne s'hybrident pas dans la nature et n'ont fourni aucune indication sur une introgression de gènes nucléaires. Des différences concernant la découverte de hôtes sont impliquées comme obstacles prézygotiques importants au flux génique entre $R$. pomonella et $R$. mendax; ce résultat conforte l'hypothèse d'une divergence sympatrique de ces mouches.

\section{References}

Berlocher S.H., 1980. An electrophoretic key for distinguishing species of the genus Rhaglotetis (Diptera: Tephritidae) as larvae, pupae, or adults. Ann. Ent. Soc. Amer. 73: 131-137.

Berlocher, S.H. \& G.L. Bush, 1982. An electrophoretic analysis of Rhagoletis (Diptera: Tephritidae) phylogeny. Syst. Zool. 31: 136-155.

Berlocher, S.H. \& D.C. Smith, 1983. Segregation and mapping of allozymes of the apple maggot fly. J. Hered. 74: 337-340.

Bierbaum, T.J. \& G.L. Bush, 1988. Divergence in key host examining and acceptance behaviors of the sibling species Rhagoletis mendax and $R$. pomonella (Dipterta: Tephritidae). pp. 26-55. In: Ecology and Management of Economically Important Fruit Flies. (M.T. Ali-Niazee, ed.). Agric. Exp. Sta. Oreg. State Univ. Special Report 830.

Boller, E.F. \& R.J. Prokopy, 1976. Bionomics and management of Rhagoletis. Ann. Rev. Ent. 21: 223-246.

Bourne, A.I., W.H. Thies \& F.R. Shaw, 1934. Some observations on long distance dispersal of apple maggot flies. J. Econ. Ent. 27: 352-355.

Bush, G.L., 1966. The taxonomy, cytology and evolution of the genus Rhagoletis in North America (Diptera: Tephritidae). MCZ, Cambridge, Mass, U.S.A.

Bush, G.L., 1969a. Sympatric host race formation and speciation in frugivorous flies of the genus Rhagoletis (Diptera: Tephritidae). Evolution. 23: 237-351.

Bush, G.L., 1969b. Mating behavior, host specificity, and the ecological significance of sibling species in frugivorous flies of the genus Rhagoletis (Diptera:Tephritidae). Am. Nat. 103: $669-672$.
Bush, G.L., 1975. Modes of animal speciation. Ann. Rev. Ecol. Syst. 6: 339-364.

Cockerham, C.C. \& B.S. Weir, 1977. Digenic descent measures for finite populations. Genet. Res. 30: 121-147.

Diehl, S.R. \& R.J. Prokopy, 1986. Host-selection behavioral differences between the fruit fly sibling species Rhagoletis pomonella and $R$. mendax (Diptera:Tephritidae). Ann. Ent. Soc. Amer. 79(1): 266-271.

Feder, J.L., C.A. Chilcote \& G.L. Bush, 1988. Genetic differentiation between sympatric host races of Rhagoletis pomonella. Nature 336: 61-64.

Feder, J.L., C.A. Chilcote \& G.L. Bush, Inheritance and linkage relationships of allozymes in the apple maggot fly. J. Hered. (In press).

Herrick, G.W., 1920. The apple maggot in New York. Cornell Univ. Agr. Exp. Sta. Bull. 402: 89-101.

Maxwell, C.W., 1968. Apple maggot adult dispersion in a New Brunswick apple orchard. J. Econ. Ent. 61: 103-106.

McCauley, D.E., 1987. Population genetic consequences of local colonization: Evidence from the milkweed beetle Tetraopes tetraophthalmus. Florida Ent. 70(1): 21-30.

McPheron, B.A., D.C. Smith \& S.H. Berlocher, 1988. Genetic differences between host races of the apple maggot fly. Nature 336: 64-66.

Menken, S.B.J., S.A. Ulenberg, 1987. Biochemical characters in agricultural entomology. Agricult. Zool. Rev. 2: $305-360$.

Nei, M., 1972. Genetic distance between populations. Am. Nat. 106: 283-292.

Neilson, W.T.A., 1971. Dispersal studies of a natural populat1on of apple maggot adults. J. Econ. Ent. 64(3): 648-653.

Phipps, C.R. \& C.O. Dirks, 1933. Dispersal of the apple maggot fly-1932 studies. J. Econ. Ent. 5: 576-582.

Prokopy, R.J., E.W. Bennett \& G.L. Bush, 1971. Mating behavior in Rhagoletis pomonella (Diptera: Tephritidae). I. Site of assembly. Canad. Ent. 103: 1405-1409.

Prokopy, R.J., E.W. Bennett \& G.L. Bush, 1972. Mating behavior in Rhagoletis pomonella (Diptera: Tephritidae). II. Temporal organization. Canad. Ent. 104: 97-104.

Prokopy, R.J. \& G.L. Bush, 1972. Apple maggot infestation of pear. J. Econ. Ent. 65: 597.

Prokopy, R.J. \& S.H. Berlocher, 1980. Establishment of Rhagoletis pomonella (Diptera : Tephritidae) on rose hips in southern New England. Can. Ent. 112: 1319-1320.

Shervis, L.J., G.M. Boush \& C.F. Koval, 1970. Infestation of sour cherries by the apple maggot: Confirmation of a previously uncertain host status. J. Econ. Ent. 63: 294-295.

Spiess. E.B., 1977. Genes in Populations. Wiley and Sons, New York. $780 \mathrm{pp}$.

Walsh, B.J., 1867. The apple-worm and the apple maggot. J. Hort. 2: 338-343.

Weir, B.S. \& C.C. Cockerham, 1984. Estimatıng F-statistics for the analysis of population structure. Evolution 38 : 1358-1370. 